OS MECANISMOS DA SUPEREXPLORAÇÃO DA FORÇA DE TRABALHO

Elizeu Serra de Araujo

Universidade Federal do Maranhão (UFMA)

\title{
OS MECANISMOS DA SUPEREXPLORAÇÃO DA FORÇA DE TRABALHO
}

Resumo: O artigo examina os mecanismos de incremento da taxa de mais-valia que, de acordo com Ruy Mauro Marini, configuram uma superexploração da força de trabalho, uma das tendências fundamentais do desenvolvimento capitalista em economias dependentes. Trata-se da intensificação do trabalho, do prolongamento da jornada de trabalho e da redução do salário abaixo do valor da força de trabalho. A característica comum aos três mecanismos é que o salário pago situa-se, em média, abaixo do valor da força de trabalho. O objetivo é, portanto, analisar a origem da divergência entre valor e preço da força de trabalho em cada um desses casos. Após a exposição do conceito de superexploração e de um breve resgate dos principais aspectos da relação entre preço e valor da força de trabalho em Marx, o artigo procura mostrar de que modo cada um dos referidos mecanismos atende ao critério adotado por Marini para caracterizar a presença da superexploração.

Palavras-chave: Superexploração, valor da força de trabalho, preço da força de trabalho, economias dependentes.

\section{THE MECHANISMS OF OVEREXPLOITATION OF LABOR POWER}

Abstract: The article examines the mechanisms of increasing the rate of surplus value which, according to Ruy Mauro Marini, configure an overexploitation of labor power, one of the fundamental tendencies of capitalist development in dependent economies. They consist of the intensification of labor, the prolongation of the working day and the reduction of wages below the value of labor power. The common feature of the three mechanisms is that, on an average, wages are below the value of labor power. The article aims to analyze the origin of divergence between value and price of labor power in each case. After exposing the concept of overexploitation and make a brief rescue of the main aspects of the relationship between price and value of labor power in Marx, we try to show how each of these mechanisms attends the criterion adopted by Marini for characterize the presence of overexploitation.

Key words: Overexploitation, value of labor power, price of labor power, dependent economies. 


\section{INTRODUÇÃO}

Nos anos recentes, o tema da superexploração da força de trabalho tem despertado o interesse de diversos estudiosos do capitalismo contemporâneo, especialmente em conexão com as perspectivas que se colocam para as economias dependentes no atual contexto. Conforme é amplamente conhecido, tal fenômeno constituiu um dos aspectos centrais das formulações da vertente marxista da teoria da dependência, no período compreendido entre a segunda metade dos anos 1960 e fins dos anos 1970. A formulação mais acabada da tese foi apresentada por Ruy Mauro Marini em sua Dialéctica de la dependencia, cuja primeira edição foi publicada em 1973. Ainda que o nível de abstração que caracteriza o tratamento da problemática na referida obra seja relativamente elevado, sua contribuição foi decisiva no sentido de pôr o acento numa das principais tendências da acumulação capitalista em economias dependentes.

Por outro lado, o tema da superexploração suscitou controvérsias, tanto no que diz respeito a aspectos propriamente teóricos quanto no tocante a sua verificação empírica. ${ }^{1}$ Lamentavelmente, esse debate acabou quase abandonado durante anos, por motivos que não cabe examinar aqui. De qualquer forma, esse fato terminou levando a que não se registrassem maiores avanços nem na frente teórica nem na aplicação do conceito na investigação de realidades particulares. É nesse sentido que a presente retomada do interesse pelo tema constitui um fato da maior importância.

Neste artigo, pretendemos examinar um aspecto teórico específico da tese da superexploração. Trata-se dos mecanismos pelos quais ela se materializa. De acordo com Marini (1973), são três esses mecanismos: a intensificação do trabalho, o prolongamento da jornada de trabalho e a redução do salário abaixo do valor da força de trabalho. ${ }^{2}$ Ainda segundo Marini (1973), a característica comum aos três mecanismos é que o salário pago situa-se, em média, abaixo do valor da força de trabalho. Nosso objetivo é, portanto, analisar a origem da divergência entre valor e preço da força de trabalho em cada um desses casos.

O trabalho está organizado da seguinte forma. Na seção seguinte, retomamos o conceito de superexploração tal como formulado por Marini e examinamos os principais aspectos da relação entre valor e preço da força de trabalho em Marx, uma vez que a divergência quantitativa entre ambos é, a nosso ver, o elemento constitutivo da categoria superexploração. Na terceira seção, examinamos a origem da defasagem do preço da força de trabalho com respeito ao seu valor em cada um dos mecanismos da superexploração. A quarta seção apresenta as principais conclusões do estudo.

\section{O CONCEITO DE SUPEREXPLORAÇÃO EM MARINI}

Comecemos indicando o elemento que, segundo Marini (1973), torna a superexploração necessária nas economias dependentes. Esse elemento corresponde às transferências de valor com que tais economias necessitam arcar sistematicamente em direção às economias capitalistas avançadas, em virtude da natureza da sua integração no mercado mundial capitalista e da troca desigual a que dá origem. ${ }^{3}$ Esse aspecto da tese, por si só, mereceria um estudo específico, que ultrapassa o objetivo aqui pretendido. ${ }^{4} \mathrm{O}$ ponto a destacar é que, segundo o autor, diante dessas transferências de valor, os capitalistas que operam nas economias dependentes buscam um "mecanismo de compensação", na forma de um incremento da massa de valor intercambiado por elas, o que, "[...] sem impedir a transferência [...], permite neutralizá-la total ou parcialmente mediante o aumento do valor realizado." (MARINI, 1973, p. 35).

O passo seguinte do argumento consiste em demonstrar que, "[...] para incrementar a massa de valor produzida, o capitalista deve necessariamente lançar mão de uma maior exploração do trabalho [...]" (MARINI, 1973, p. 36). A razão apontada pelo autor para isso é que a desvantagem que as economias dependentes possuem no comércio internacional é uma decorrência do menor nível de desenvolvimento da força produtiva do trabalho que as caracteriza. Assim, na ausência de condições objetivas que Ihes permitam galgar níveis mais elevados de produtividade, de modo a encurtar a distância entre o preço de produção e o valor das mercadorias que exportam, procuram compensar aquela desvantagem através de mecanismos que implicam um aumento da exploração da força de trabalho:

\begin{abstract}
O que aparece claramente, pois, é que as nações desfavorecidas pela troca desigual não buscam tanto corrigir o desequilíbrio entre os preços e o valor de suas mercadorias exportadas (o que implicaria um esforço redobrado para aumentar a capacidade produtiva do trabalho), mas, antes, compensar a perda de rendas gerada pelo comércio internacional, através do recurso a uma maior exploração do trabalhador. (MARINI, 1973, p. 36-37).
\end{abstract}

A ideia de "maior exploração" que aparece nessas passagens não é, em primeira instância, a de um aumento da taxa de mais-valia - embora esse resultado também esteja implicado, como se verá adiante -, e sim a de um aumento do dispêndio de trabalho, de força física, por parte do trabalhador. $\mathrm{O}$ que está em questão, portanto, são os métodos de extração de mais-valia dos quais os capitalistas nas 
economias dependentes podem efetivamente lançar mão para compensar a sua perda de mais-valia, uma vez que a possibilidade de obtenção de níveis de produtividade semelhantes aos das economias avançadas está praticamente descartada.

Marini (1973, p. 38-39, grifos do autor) passa a expor esses métodos:

O aumento da intensidade do trabalho aparece, nessa perspectiva, como um aumento da mais-valia, obtido através de uma maior exploração do trabalhador e não do incremento de sua capacidade produtiva. O mesmo se poderia dizer do prolongamento da jornada de trabalho, isto é, do aumento da mais-valia absoluta em sua forma clássica; diferentemente do primeiro, trata-se aqui de aumentar simplesmente o tempo de trabalho excedente, que é aquele em que o operário continua produzindo depois de haver criado um valor equivalente ao dos meios de subsistência para seu próprio consumo. Haveria de assinalar, finalmente, um terceiro procedimento, que consiste em reduzir o consumo do operário além de seu limite normal, pelo qual "o fundo necessário de consumo do operário se converte de fato, dentro de certos limites, em um fundo de acumulação de capital", implicando assim um modo específico de aumentar o tempo de trabalho excedente. ${ }^{5}$

Ocorre que esses métodos de incremento do mais-trabalho e, portanto, da mais-valia, que são os que prevalecem nas economias dependentes, configuram uma superexploração da força de trabalho. Marini (1973, p. 41-42) explica por quê:

Importa assinalar [... que, nos três mecanismos considerados, a característica essencial é dada pelo fato de que são negadas ao trabalhador as condições necessárias para repor o desgaste de sua força de trabalho: nos dois primeiros casos, porque se lhe obriga a um dispêndio de força de trabalho superior ao que deveria proporcionar normalmente, provocando-se assim seu esgotamento prematuro; no último, porque se lhe retira inclusive a possibilidade de consumir o estritamente indispensável para conservar sua força de trabalho em estado normal. Em termos capitalistas, esses mecanismos [...] significam que o trabalho é remunerado abaixo de seu valor, e correspondem, pois, a uma superexploração do trabalho.

A mesma explicação é encontrada no pósescrito a Dialéctica de la dependencia:
[...] a superexploração se define [...] pela maior exploração da força física do trabalhador, em contraposição à exploração resultante do aumento de sua produtividade, e tende normalmente a expressar-se no fato de que a força de trabalho se remunere abaixo de seu valor real. (MARINI, 1973, p. 92-93, grifo nosso). ${ }^{6}$

Aí está o que, em nosso entender, constitui o elemento definidor da superexploração, a saber, o pagamento de um salário inferior ao valor da força de trabalho. O conceito não se refere, portanto, à existência de uma taxa de mais-valia especialmente elevada, e sim a uma particular configuração da relação capitalista na qual o preço da força de trabalho situa-se, em média, abaixo do seu valor. Tanto é assim que, em determinada formação social em que, por hipótese, a força de trabalho seja remunerada aproximadamente de acordo com o seu valor, a taxa de mais-valia - a relação entre o maistrabalho e o trabalho necessário ou entre a maisvalia e o capital variável -, baseada principalmente no aumento da produtividade do trabalho, pode, em princípio, ser superior à de outra, em que prevalece o recurso ao aumento extensivo ou intensivo da jornada de trabalho. ${ }^{7}$

Enfatizemos que o incremento da mais-valia obtido mediante o aumento da produtividade do trabalho não configura superexploração. $O$ aumento da mais-valia decorre, nesse caso, da redução do tempo de trabalho necessário, vale dizer, da redução do valor da força de trabalho. Portanto, aqui, não é necessário que o preço da força de trabalho se situe abaixo do seu valor. Pode corresponder a este último ou, eventualmente, situar-se acima dele, tudo dependendo "[...] do peso relativo que a pressão do capital, de um lado, e a resistência do trabalhador, de outro, jogam no prato da balança." (MARX, 1984a, p. 115).

Posto isso, é necessário fundamentar a legitimidade da utilização de um conceito distinto do conceito marxiano de exploração. Como se sabe, toda a argumentação de Marx acerca da exploração capitalista é construída com base no pressuposto de que o preço da força de trabalho corresponde ao seu valor. Evidentemente, isso não expressa a generalidade das condições em que se dá a compra da mercadoria força de trabalho pelo capital. Constitui, antes, um recurso útil a Marx para demonstrar que, ainda nessa circunstância, a força de trabalho não se apropria da totalidade do valor criado por ela. Em outros termos, que o valor da força de trabalho é necessariamente inferior ao valor criado por ela ao longo do processo de produção.

Temos aí, por outro lado, a razão específica por que Marx não trata sistematicamente do fenômeno da superexploração. Isso se deve exclusivamente ao nível de abstração em que ele leva a cabo sua investigação das leis de movimento do capital. ${ }^{8}$ 
Tanto é que o próprio Marx, em certas ocasiões, faz referência a discrepâncias entre o preço e o valor da força de trabalho. Já um exame detalhado dessa possibilidade o obrigaria a estender os limites de sua investigação de modo a abranger os fenômenos ligados à concorrência.

Em nosso caso, em contrapartida, em que está em foco o movimento do capital em economias dependentes, é indispensável aprofundar o significado da divergência quantitativa entre preço e valor da força de trabalho. Para tanto, é necessário delimitar o estatuto teórico dessas duas categorias.

Em total coerência com sua teoria do valor, Marx (1983a, p. 141) sustenta que

[...] [o] valor da força de trabalho, como o de toda outra mercadoria, é determinado pelo tempo de trabalho necessário à produção, portanto também reprodução, desse artigo específico.

Ora, esse tempo de trabalho não é outro senão o necessário à produção dos meios de subsistência que entram no consumo habitual do trabalhador.

Nesses termos, o valor da força de trabalho depende de dois elementos: (i) da quantidade de meios de subsistência necessários; e (ii) do valor desses meios de subsistência. Variações no valor dos meios de subsistência são explicadas por variações na produtividade do trabalho. Trata-se de aumentos da produtividade nos ramos que, direta ou indiretamente, produzem os meios de subsistência necessários. Variações na quantidade de meios de subsistência, por sua vez, são explicadas (i) por variações na extensão ou na intensidade do trabalho; ou (ii) pela incorporação de novas necessidades à cesta de consumo do trabalhador, levando em conta que nesse conjunto estão compreendidos tanto o elemento físico quanto o histórico-moral. Em geral, o procedimento de Marx consiste em considerar dados todos os fatores que interferem na massa de meios de subsistência e atribuir as variações do valor da força de trabalho às variações no valor desses meios. Seu procedimento é sintetizado na seguinte passagem:

O valor da força de trabalho é determinado pelo valor dos meios de subsistência habitualmente necessários ao trabalhador médio. A massa desses meios de subsistência, ainda que sua forma possa variar, em determinada época de determinada sociedade é dada, podendo, portanto, ser tratada como uma grandeza constante. O que muda é o valor dessa massa. (MARX, 1984a, p. 113).

O preço da força de trabalho é, em primeira instância, apenas o valor da força de trabalho expresso em dinheiro. Supõe-se aqui que demanda e oferta de força de trabalho coincidam. Em um nível de abstração menor, entretanto, o preço da força de trabalho não coincide necessariamente com o seu valor, oscilando em torno dele. Suas variações dependem da relação entre a demanda e a oferta de força de trabalho. Ressaltemos que o valor da força de trabalho é determinado independentemente dessas duas variáveis. Uma consequência desse ponto de vista é que os fatores que interferem na demanda e na oferta de força de trabalho incidem especificamente sobre as variações do preço dessa mercadoria - e não sobre o seu valor (e nisso Marx, mais uma vez, mantém para a mercadoria força de trabalho a regra válida para as demais mercadorias). Esses fatores podem ser condensados na expansão do exército industrial de reserva, que, por sua vez, estabelece as condições em que se dá a luta da classe trabalhadora ${ }^{9}$ em torno da fixação do salário. ${ }^{10}$

Uma divergência do preço da força de trabalho com respeito ao seu valor - mais precisamente, a fixação de um salário inferior ao valor da força de trabalho - implica, de acordo com Marx (1983a), que a reprodução da força de trabalho ocorre de maneira atrofiada. Excluídos desvios temporários, a persistência dessa situação por um longo período só é possível se de alguma forma se assegura a substituição dos trabalhadores. Assim, conquanto o preço da força de trabalho, em primeira instância, tenda a convergir para o seu valor (como é a regra para as mercadorias em geral), podem-se configurar situações em que tal convergência se veja bloqueada por fatores estruturais prevalecentes em certas formações sociais.

Ora, esse é precisamente o caso das economias dependentes latino-americanas, de acordo com Marini. O principal fator responsável por essa particular situação é a expansão que o exército industrial de reserva experimentou nessas economias. ${ }^{11}$ É esse fenômeno que reduz concretamente para a classe trabalhadora a possibilidade de êxito em suas reivindicações de um salário correspondente ao valor da força de trabalho (MARINI, 1979a). Ao mesmo tempo, ao possibilitar o pagamento de um salário inferior a esse nível, o crescimento do exército industrial de reserva desestimula o capital a recorrer ao uso de maquinaria em larga escala, limitando o campo para o aumento da produtividade do trabalho nessas

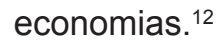

Da perspectiva da realização da produção, a possibilidade de permanência do hiato entre o preço e o valor da força de trabalho é explicada pelo papel secundário que o consumo individual dos trabalhadores desempenhou historicamente nas economias latino-americanas (MARINI, 1973). Assim, referindo-se à economia exportadora, Marini (1973, p. 52) argumenta:

Como a circulação se separa da produção e se efetua basicamente no 
âmbito do mercado externo, o consumo individual do trabalhador não interfere na realização do produto, ainda que determine a taxa de mais-valia. Em consequência, a tendência natural do sistema será a de explorar ao máximo a força de trabalho do operário, sem preocupar-se em criar as condições para que este a reponha, sempre e quando se lhe possa substituir mediante a incorporação de novos braços ao processo produtivo.

Ainda segundo o autor, essa característica do desenvolvimento capitalista na região, bastante clara no caso da economia exportadora, não se teria modificado essencialmente na fase da industrialização (MARINI, 1973).

\section{A DIVERGÊNCIA ENTRE PREÇO E VALOR DA FORÇA DE TRABALHO NOS DIFERENTES MECANISMOS DA SUPEREXPLORAÇÃO}

O objetivo desta seção consiste em analisar a origem da divergência entre preço e valor da força de trabalho em cada um dos mecanismos da superexploração identificados por Marini. Em outras palavras, em precisar de que modo cada um desses mecanismos atende ao critério adotado pelo autor para caracterizar a presença da superexploração. Os dois primeiros mecanismos analisados pertencem ao âmbito do consumo da força de trabalho, enquanto o terceiro pertence ao âmbito da compra e venda dessa mercadoria.

\subsection{Prolongamento da jornada de trabalho}

O primeiro aspecto a notar é que o valor novo (soma do capital variável com a mais-valia) produzido durante a jornada de trabalho cresce proporcionalmente ao aumento extensivo desta, supondo-se constante a intensidade do trabalho. Por outro lado, se a produtividade do trabalho é suposta constante, o valor da força de trabalho permanece inalterado. Nesses termos, em caso de prolongamento da jornada de trabalho, todo o incremento do valor novo se destinará a aumentar a mais-valia.

Aqui, como no tratamento dos demais mecanismos pelos quais se pode obter um incremento da mais-valia, Marx adota o pressuposto de que o valor da força de trabalho varia apenas com o valor dos meios de subsistência habituais do trabalhador, cuja quantidade é, para todos os efeitos, tomada como dada. Pretendemos, no que se segue, levantar esse pressuposto e considerar a possibilidade de uma variação na quantidade daqueles meios de subsistência.

Ora, o prolongamento da jornada de trabalho - a forma clássica da mais-valia absoluta - produz precisamente a necessidade de um acréscimo na quantidade de meios de subsistência, em função do maior desgaste da força de trabalho que implica. Considerando que a determinação da magnitude do valor da força de trabalho toma por base uma duração normal do trabalho, ${ }^{13} \mathrm{o}$ prolongamento desta tem como contrapartida o aumento do valor da força de trabalho. Marx, aliás, sustenta que o valor da força de trabalho não apenas aumenta, mas o faz em proporção superior ao aumento da jornada. Em suas palavras:

O valor da força de trabalho, porque isso se dá com seu desgaste, aumenta com a duração de seu funcionamento e em proporção maior do que o incremento da duração de seu funcionamento. (MARX, 1984a, p. 135).

Nessas circunstâncias, é perfeitamente possível que o aumento do salário, na medida em que depende da relação de forças nas condições específicas de evolução do exército industrial de reserva, não seja suficiente para equiparar-se ao valor acrescido da força de trabalho. Estamos diante de uma situação de discrepância entre o preço e o valor da força de trabalho decorrente de uma variação do próprio valor. A seguinte passagem de Marx (1984a, p. 118) se refere a esse caso:

Com a jornada de trabalho prolongada, o preço da força de trabalho pode cair abaixo de seu valor, embora nominalmente permaneça inalterado ou mesmo suba. É que o valor diário da força de trabalho [...] é calculado sobre sua duração média, ou seja, sobre a duração normal da vida de um trabalhador e sobre uma correspondente transformação normal, ajustada à natureza humana, de substância vital em movimento. Até certo ponto, o desgaste maior de força de trabalho, inseparável do prolongamento da jornada de trabalho, pode ser compensado por maior [remuneração]. ${ }^{14}$

A Tabela 1 mostra, a partir de uma situação hipotética inicial, duas possibilidades de evolução do valor da força de trabalho em caso de prolongamento da jornada.

A jornada de trabalho é inicialmente fixada em 8 horas, durante as quais é produzido um valor novo de $\$ 60$. O trabalho necessário é igual a 4 horas, ou o valor da força de trabalho é igual a \$30. Essas são também as magnitudes do mais-trabalho e da mais-valia. A taxa de mais-valia é, portanto, de $100 \%$. Um aumento da jornada de trabalho para 10 horas (supondo constante a intensidade do trabalho) elevaria o valor novo produzido para $\$ 75$.

Consideremos o que acontece com o valor da força de trabalho. Na situação 2, ele permanece inalterado - o que indica que a quantidade de meios 
Tabela 1 - Valor e preço da força de trabalho com o prolongamento da jornada de trabalho

\begin{tabular}{cccccccccc}
\hline & $\begin{array}{c}\text { Jornada } \\
\text { de } \\
\text { trabalho }\end{array}$ & $\begin{array}{c}\text { Valor } \\
\text { novo }\end{array}$ & $\begin{array}{c}\text { Trabalho } \\
\text { necessário } \\
\mathbf{( 1 )}\end{array}$ & $\begin{array}{c}\text { Valor da } \\
\text { força de } \\
\text { trabalho }\end{array}$ & $\begin{array}{c}\text { Trabalho } \\
\text { necessário } \\
\mathbf{( 2 )}\end{array}$ & $\begin{array}{c}\text { Preço da } \\
\text { força de } \\
\text { trabalho }\end{array}$ & $\begin{array}{c}\text { Mais- } \\
\text { trabalho }\end{array}$ & $\begin{array}{c}\text { Mais- } \\
\text { valia }\end{array}$ & $\begin{array}{c}\text { Taxa } \\
\text { de } \\
\text { mais- } \\
\text { valia }\end{array}$ \\
\hline 1 & $8 \mathrm{~h}$ & 60 & $4 \mathrm{~h}$ & 30 & $4 \mathrm{~h}$ & 30 & $4 \mathrm{~h}$ & 30 & $100 \%$ \\
2 & $10 \mathrm{~h}$ & 75 & $4 \mathrm{~h}$ & 30 & $4 \mathrm{~h}$ & 30 & $6 \mathrm{~h}$ & 45 & $150 \%$ \\
3 & $10 \mathrm{~h}$ & 75 & $5 \mathrm{~h}$ & 37,50 & $4,80 \mathrm{~h}$ & 36 & $5,20 \mathrm{~h}$ & 39 & $108 \%$ \\
\hline
\end{tabular}

Fonte: Elaboração do autor.

(1) Correspondente ao valor da força de trabalho.

(2) Correspondente ao preço da força de trabalho.

de subsistência necessários permanece constante. O preço da força de trabalho, de igual modo, mantém-se constante, refletindo o pressuposto de Marx de correspondência entre preço e valor. $O$ mais-trabalho eleva-se a 6 horas, ou a mais-valia a $\$ 45$. A taxa de mais-valia eleva-se a $150 \%$.

$\mathrm{Na}$ situação 3 , o valor da força de trabalho aumenta proporcionalmente ao aumento da jornada de trabalho $(25 \%)$, situando-se em $\$ 37,50$, refletindo o aumento na quantidade de meios de subsistência, cuja produção exige agora 5 horas (o novo tempo de trabalho necessário). Diferentemente da situação anterior, o preço da força de trabalho também aumenta, só que em proporção menor que seu valor. O novo preço, de $\$ 36$, corresponde a $4,80 \mathrm{~h}$ de trabalho necessário, enquanto a mais-valia, de $\$$ 39 , corresponde a $5,20 \mathrm{~h}$ de mais-trabalho. ${ }^{15}$ Assim, embora mais elevado, o preço da força de trabalho situa-se abaixo do seu valor, sinalizando uma piora nas condições de vida do trabalhador, na medida em que este não consegue, com o novo salário, adquirir a totalidade dos meios de subsistência necessários para repor o maior desgaste de sua força de trabalho. Como vimos, isso exigiria uma elevação do trabalho necessário para 5 horas, enquanto o trabalhador dispõe de apenas 4,80h.

Temos aí uma situação em que o prolongamento da duração do trabalho configura uma situação de superexploração, nos termos colocados por Marini.

\subsection{Intensificação do trabalho}

Aintensificação do trabalho constitui uma reação do capital à luta dos trabalhadores pela imposição de limites à jornada de trabalho. Com efeito,

[...] a redução forçada dajornada de trabalho [...] impõe maior dispêndio de trabalho no mesmo tempo, tensão mais elevada da força de trabalho, preenchimento mais denso dos poros da jornada de trabalho [...] (MARX, 1984a, p. 33).

Portanto, em determinado tempo de trabalho se materializa uma quantidade de trabalho maior do que na jornada de intensidade normal:

Essa compressão de maior massa de trabalho em dado período de tempo conta, agora, pelo que ela é: como maior quantum de trabalho. Ao lado da medida do tempo de trabalho como "grandeza extensiva", surge agora a medida de seu grau de condensação. A hora mais intensa da jornada de trabalho de 10 horas contém, agora, tanto ou mais trabalho, isto é, força de trabalho despendida, do que a hora mais porosa da jornada de trabalho de 12 horas. (MARX, 1984a, p. 33).

Em consequência, a intensificação do trabalho resulta no aumento do valor global produzido no período de tempo considerado. A forma mais simples de compreender esse mecanismo é confrontá-lo com um aumento da produtividade do trabalho:

A jornada de trabalho mais intensiva corporifica-se, portanto, em mais produtos do que a menos intensiva, com igual número de horas. Com força produtiva aumentada, em verdade a mesma jornada de trabalho fornece, também, mais produtos. No último caso, porém, cai o valor do produto unitário, porque custa menos trabalho que antes; no primeiro caso, ele permanece inalterado porque o produto, depois como antes, custa a mesma quantidade de trabalho. O número de produtos, aqui, aumenta sem cair seu preço. Com seu número cresce a soma de seus preços, enquanto lá a mesma soma de valor representa-se numa massa de produtos apenas aumentada. Para um número de horas constante, a jornada de trabalho mais intensiva se corporifica, pois, em produto-valor mais alto [...]. Seu produto-valor varia com os desvios de sua intensidade do grau socialmente normal. [... $]^{16}$

Se a intensidade do trabalho se elevasse em todos os ramos industriais ao mesmo tempo e na mesma medida, o novo grau de intensidade mais alto tornar-se-ia o grau normal, socialmente habitual, e cessaria com isso de ser contado como grandeza extensiva. (MARX, 1984a, p. 116-117).

Em resumo, enquanto um aumento da produtividade do trabalho deixa inalterado 0 
valor novo produzido em determinado tempo de trabalho e reduz o valor da mercadoria individual, a intensificação do trabalho implica um aumento do valor novo produzido, deixando inalterado o valor da mercadoria individual (assemelhando-se nesse aspecto a uma extensão absoluta da jornada de trabalho).

No entanto, como método de incremento da taxa de mais-valia a intensificação do trabalho opera de forma semelhante ao aumento da produtividade, isto é, permite o encurtamento do tempo de trabalho necessário e, em consequência, a ampliação do tempo de mais-trabalho. A semelhança entre os dois métodos no tocante à forma como promovem o aumento do grau de exploração do trabalho é claramente apontada por Marx (1984a, p. 120, grifo nosso):

\begin{abstract}
A força produtiva do trabalho aumentada e sua crescente intensidade atuam uniformemente em um mesmo sentido. Ambas ampliam a massa de produtos elaborada em cada período de tempo. Ambas reduzem, pois, a parte da jornada de trabalho de que o trabalhador precisa para a produção de seus meios de subsistência ou seu equivalente. ${ }^{17}$
\end{abstract}

Vejamos como isso ocorre. Suponhamos que a jornada de trabalho seja uma grandeza fixa e que a produtividade do trabalho permaneça inalterada. Suponhamos agora que ocorra um aumento da intensidade do trabalho. De que maneira o período de tempo de que o trabalhador necessita para reproduzir um equivalente ao valor de sua força de trabalho poderia ser reduzido?

A jornada de trabalho mais intensa permite precisamente que, no mesmo tempo, se produza uma magnitude de valor maior ou, o que dá no mesmo, que determinada magnitude de valor se produza num tempo menor. Retomando o exemplo anterior, seja a jornada de trabalho fixada em 8 horas e o valor novo nela produzido de $\$ 60$. O trabalho necessário corresponde a 4 horas ou o valor da força de trabalho a \$30; o mais-trabalho é também de 4 horas ou a mais-valia igual a $\$ 30$, implicando uma taxa de mais-valia de $100 \%$. Se, por imposição legal, é impossível estender a jornada em termos absolutos, um aumento da intensidade do trabalho permitiria que, nas mesmas oito horas, se produzisse um valor novo, digamos, $25 \%$ maior, ou seja, de $\$$ 75. Para reproduzir o equivalente ao valor de sua força de trabalho (\$30), o trabalhador necessitaria agora, em vez de 4 horas, de apenas 3,20h. O mais- trabalho passaria a $4,80 \mathrm{~h}$, correspondendo a $\$ 45$. A taxa de mais-valia ascenderia a 150\%. A Tabela 2 resume isso.

Pode causar estranheza na Tabela o fato de que o valor da força de trabalho se mantém inalterado (\$ 30) enquanto o tempo de trabalho necessário se reduz. Mas isso é da própria natureza da intensificação do trabalho e não deveria ser considerado mais estranho que o fenômeno retratado nas duas primeiras colunas - a produção de um valor novo maior numa jornada de magnitude fixa. ${ }^{18}$

No raciocínio anterior, o valor da força de trabalho foi suposto constante, a despeito do aumento da intensidade do trabalho, com a finalidade de expormos o modo pelo qual esse mecanismo resulta num aumento da taxa de mais-valia. Ocorre que o aumento da intensidade do trabalho requer um aumento do volume de meios de subsistência necessários, devido ao aumento do desgaste da força de trabalho. Qual a consequência disso para o valor da força de trabalho? O valor da força de trabalho é definido para um grau de intensidade do trabalho considerado normal. Assim, um desvio desse grau normal se expressa num aumento do valor da força de trabalho. Isso fica claro nesta passagem de Marx citada por Marini (1973, p. 42): "Toda variação na magnitude, extensiva ou intensiva, do trabalho afeta [...] o valor da força de trabalho, na medida em que acelera seu desgaste."19

Aqui, como no caso de aumento da jornada, pode ocorrer que o aumento do salário não acompanhe o aumento do valor da força de trabalho. Marx (1984a, p. 117) considera essa possibilidade ao analisar as implicações de um aumento da intensidade:

É claro: se varia o produto-valor da jornada de trabalho [...] ambas as partes desse produto-valor, preço da força de trabalho e mais-valia, podem crescer simultaneamente, seja em grau igual ou desigual.

Em seguida, faz a seguinte observação:

Aumento do preço da força de trabalho não implica aqui, necessariamente, elevação de seu preço acima de seu valor. Ele pode, pelo contrário, ser acompanhado por uma queda abaixo de seu valor. Isso ocorre sempre que o aumento do preço da força de trabalho não compensa seu desgaste acelerado. (MARX, 1984a, p. 117, grifos nossos).

Tabela 2 - Aumento da intensidade do trabalho

\begin{tabular}{cccccccc}
\hline $\begin{array}{c}\text { Jornada de } \\
\text { trabalho }\end{array}$ & $\begin{array}{c}\text { Valor } \\
\text { novo }\end{array}$ & $\begin{array}{c}\text { Trabalho } \\
\text { necessário }\end{array}$ & $\begin{array}{c}\text { Valor da força de } \\
\text { trabalho }\end{array}$ & Mais-trabalho & Mais-valia & $\begin{array}{c}\text { Taxa de mais- } \\
\text { valia }\end{array}$ \\
\hline 1 & $8 \mathrm{~h}$ & 60 & $4 \mathrm{~h}$ & 30 & $4 \mathrm{~h}$ & 30 \\
2 & $8 \mathrm{~h}$ & 75 & $3,20 \mathrm{~h}$ & 30 & $4,80 \mathrm{~h}$ & $100 \%$ \\
\hline
\end{tabular}

Fonte: Elaboração do autor. 
Tabela 3 - Valor e preço da força de trabalho com o aumento da intensidade do trabalho

\begin{tabular}{cccccccccc}
\hline $\begin{array}{c}\text { Jornada de } \\
\text { trabalho }\end{array}$ & $\begin{array}{c}\text { Valor } \\
\text { novo }\end{array}$ & $\begin{array}{c}\text { Trabalho } \\
\text { necessário } \\
\mathbf{( 1 )}\end{array}$ & $\begin{array}{c}\text { Valor da } \\
\text { força de } \\
\text { trabalho }\end{array}$ & $\begin{array}{c}\text { Trabalho } \\
\text { necessário } \\
\mathbf{( 2 )}\end{array}$ & $\begin{array}{c}\text { Preço da } \\
\text { força de } \\
\text { trabalho }\end{array}$ & $\begin{array}{c}\text { Mais- } \\
\text { trabalho }\end{array}$ & $\begin{array}{c}\text { Mais- } \\
\text { valia }\end{array}$ & $\begin{array}{c}\text { Taxa } \\
\text { de } \\
\text { mais- } \\
\text { valia }\end{array}$ \\
\hline 1 & $8 \mathrm{~h}$ & 60 & $4 \mathrm{~h}$ & 30 & $4 \mathrm{~h}$ & 30 & $4 \mathrm{~h}$ & 30 & $100 \%$ \\
2 & $8 \mathrm{~h}$ & 75 & $3,20 \mathrm{~h}$ & 30 & $3,20 \mathrm{~h}$ & 30 & $4,80 \mathrm{~h}$ & 45 & $150 \%$ \\
3 & $8 \mathrm{~h}$ & 75 & $4 \mathrm{~h}$ & 37,50 & $3,84 \mathrm{~h}$ & 36 & $4,16 \mathrm{~h}$ & 39 & $108 \%$ \\
\hline
\end{tabular}

Fonte: Elaboração do autor.

(1) Correspondente ao valor da força de trabalho.

(2) Correspondente ao preço da força de trabalho.

Tabela 4 - Redução do salário abaixo do valor da força de trabalho

\begin{tabular}{cccccccccc}
\hline $\begin{array}{c}\text { Jornada } \\
\text { de }\end{array}$ & $\begin{array}{c}\text { Valor } \\
\text { novo }\end{array}$ & $\begin{array}{c}\text { Trabalho } \\
\text { necessário } \\
\text { trabalho }\end{array}$ & $\begin{array}{c}\text { Valor da } \\
\text { força de } \\
\text { trabalho }\end{array}$ & $\begin{array}{c}\text { Trabalho } \\
\text { necessário } \\
(2)\end{array}$ & $\begin{array}{c}\text { Preço da } \\
\text { força de } \\
\text { trabalho }\end{array}$ & $\begin{array}{c}\text { Mais- } \\
\text { trabalho }\end{array}$ & $\begin{array}{c}\text { Mais- } \\
\text { valia }\end{array}$ & $\begin{array}{c}\text { Taxa de } \\
\text { mais-valia }\end{array}$ \\
\hline 1 & $8 \mathrm{~h}$ & 60 & $4 \mathrm{~h}$ & 30 & $4 \mathrm{~h}$ & 30 & $4 \mathrm{~h}$ & 30 \\
2 & $8 \mathrm{~h}$ & 60 & $4 \mathrm{~h}$ & 30 & $3,20 \mathrm{~h}$ & 24 & $4,80 \mathrm{~h}$ & 36 \\
\hline
\end{tabular}

Fonte: Elaboração do autor.

(1) Correspondente ao valor da força de trabalho.

(2) Correspondente ao preço da força de trabalho.

$\mathrm{Na}$ Tabela 3, ficam claros os movimentos do valor e do preço da força de trabalho em consequência de um aumento da intensidade.

Na situação 2, reproduzida da tabela anterior, o valor da força de trabalho permanece inalterado (o que indica que a quantidade de meios de subsistência necessários permanece constante). O preço da força de trabalho também permanece inalterado. Na situação 3, em contrapartida, o valor da força de trabalho aumenta proporcionalmente ao aumento da intensidade, refletido no aumento do valor novo produzido, isto é, $25 \%$, subindo para $\$ 37,50$, correspondendo a um tempo de trabalho necessário de 4 horas. O preço da força de trabalho também aumenta, mas em menor proporção que seu valor, ou seja, para $\$ 36$, o que exige um tempo de trabalho necessário de $3,84 \mathrm{~h} .{ }^{20}$ Configura-se uma superexploração da força de trabalho, na medida em que, como no caso anterior de aumento extensivo da jornada, o preço referido não assegura ao trabalhador a reprodução normal de sua força de trabalho.

\subsection{Redução do salário abaixo do valor da força de trabalho}

Suponhamos que o valor novo produzido permaneça constante (dada a hipótese de que a duração da jornada de trabalho e seu grau de intensidade permanecem inalterados). Suponhamos também que o valor dos meios de subsistência permaneça constante (dada a hipótese de produtividade do trabalho constante). Se o volume desses meios de subsistência também permanece constante (dada a hipótese de jornada e intensidade constantes), o valor da força de trabalho permanece inalterado. Nesses termos, uma redução do salário implicará um aumento proporcional da mais-valia. A Tabela 4 mostra isso.
O preço da força de trabalho, inicialmente igual a $\$ 30$, é reduzido para $\$ 24$, sem que tenha havido qualquer redução no valor da força de trabalho. Na situação suposta, o trabalhador necessita de um tempo menor para reproduzir o equivalente ao seu salário, ou seja, 3,20h em vez de 4 horas. Isso permite que o mais-trabalho se eleve para $4,80 \mathrm{~h}$, com o que a taxa de mais-valia sobe para $150 \%$. No entanto, a redução ocorrida no tempo de trabalho necessário não se deve a um aumento da produtividade do trabalho (como é o caso na forma clássica da mais-valia relativa), e sim ao rebaixamento forçado do salário (o novo nível salarial só permite ao trabalhador dispor de uma quantidade menor de meios de subsistência).

O mais-trabalho neste caso apenas seria prolongado por ultrapassar seus limites normais, seu domínio só se expandiria usurpando parte do domínio do trabalho necessário. (MARX, 1983a, p. 250). ${ }^{21}$

Que a compressão do salário abaixo do valor da força de trabalho implica aumento da mais-valia fica claro em certas passagens de Marx. Em Teorias da mais-valia, por exemplo, se pode ler:

A mais-valia pode ser acrescida pela mera compressão do salário abaixo do nível tradicional, embora não se prolongue a jornada, nem se desenvolva a produtividade do trabalho. (MARX, 1983b, p. 451).

Do mesmo modo, lemos no capítulo $\mathrm{X}$ do livro I de O capital:

Por outro lado, a grandeza do maistrabalho é evidentemente dada, com dada grandeza da jornada de trabalho e dado valor da força de trabalho. O valor da força de trabalho, isto é, 
o tempo de trabalho exigido para produzi-la, determina o tempo de trabalho necessário para reprodução de seu valor. Se 1 hora de trabalho se representa num quantum de ouro de $1 / 2$ xelim ou 6 pence e o valor da força de trabalho monta a 5 xelins, o trabalhador tem de trabalhar 10 horas por dia para repor o valor diário de sua força de trabalho pago pelo capital ou para produzir um equivalente do valor dos seus meios de subsistência diariamente necessários. Com o valor desses meios de subsistência é dado o valor de sua força de trabalho, com o valor de sua força de trabalho é dado seu tempo de trabalho necessário. Agrandeza do maistrabalho obtém-se, porém, subtraindo da jornada de trabalho total o tempo de trabalho necessário. Subtraindo-se 10 horas de 12 ficam 2, e não se pode ver como, nas condições dadas, o maistrabalho pode ser prolongado além de 2 horas. $\mathrm{Na}$ verdade, o capitalista pode pagar ao trabalhador, em vez de 5 xelins, 4 xelins e 6 pence ou menos ainda. Para reproduzir esse valor de 4 xelins e 6 pence bastariam 9 horas de trabalho, cabendo assim ao maistrabalho 3 horas em vez de 2 da jornada de trabalho de 12 horas e aumentandose a própria mais-valia de 1 xelim para 1 xelim e 6 pence. (MARX, 1983a, p. 249250 , grifo nosso). ${ }^{22}$

A compressão do salário nos termos expostos joga um papel importante no movimento da acumulação de capital:

Nas seções sobre a produção de maisvalia, foi suposto constantemente que o salário era pelo menos igual ao valor da força de trabalho. A redução forçada do salário abaixo desse valor [...] transforma, de fato, dentro de certos limites, o fundo necessário de consumo do trabalhador em um fundo de acumulação de capital. (MARX, 1984a, p. 178).

O pressuposto de correspondência entre o preço e o valor constitui, assim, a razão exclusiva por que Marx não considera o caso em apreço em sua investigação.

Apesar do papel importante que esse método desempenha no movimento real do salário, ele é aqui excluído pelo pressuposto de que as mercadorias, inclusive, portanto, a força de trabalho, sejam compradas e vendidas por seu pleno valor. (MARX, 1983a, p. 250).

Assim, Marx não o inclui na análise geral do capital, remetendo-o à análise da concorrência. ${ }^{23}$

Em contrapartida, a investigação de situações concretas do movimento da acumulação de capital não pode omitir esse fator, de inegável importância nas economias dependentes (e não apenas nelas).

Temos, então, um terceiro mecanismo pelo qual se configura a superexploração. Notese, porém, que, diferentemente do que ocorre no caso do prolongamento da jornada e no da intensificação do trabalho, aqui a divergência entre o valor e o preço da força de trabalho não advém do aumento do primeiro, e sim da redução do último. Independentemente disso, esse mecanismo tem em comum com os anteriores o fato de que, ao implicar o pagamento de um salário inferior ao valor da força de trabalho, conduz igualmente a uma reprodução atrofiada da força de trabalho.

\section{CONCLUSÃO}

A retomada do tema da superexploração da força de trabalho constitui um elemento central no debate acerca das perspectivas do desenvolvimento capitalista nas economias dependentes. A preocupação deste artigo consistiu em analisar mais de perto um aspecto fundamental para a compreensão dessa categoria, a saber, a divergência que implica entre preço e valor da força de trabalho, procurando mostrar como tal divergência se origina em cada um dos diferentes mecanismos em que se materializa a superexploração.

Mostramos que, nos casos do prolongamento da jornada de trabalho e da intensificação do trabalho, essa divergência resulta do fato de que o aumento do valor da força de trabalho, decorrente do aumento do volume de meios de subsistência necessários para repor o desgaste da força de trabalho, não é acompanhado de um aumento proporcional do salário. No terceiro dos mecanismos examinados, a divergência advém do próprio rebaixamento do salário frente a um valor constante da força de trabalho.

As razões de um crescimento menos que proporcional do salário, no caso dos dois primeiros mecanismos, e do seu rebaixamento, no caso do terceiro, remetem a fatores próprios à formação social considerada. No caso das economias dependentes, o elemento explicativo fundamental reside na expansão do seu exército industrial de reserva. Com efeito, é esse fenômeno que, ao delimitar as condições reais em que se manifesta a combatividade da classe trabalhadora, reduz em grande medida a capacidade desta de obter êxito em suas reivindicações de uma remuneração que pelo menos compense o maior desgaste de sua força de trabalho associado ao aumento da jornada ou da intensidade do trabalho, e que condiciona a imposição de reduções salariais, em ambos os casos comprometendo a reprodução da força de trabalho.

Essa tendência do exército industrial de reserva explica, em consequência, por que a reprodução do capital nas economias dependentes, 
em vez de basear-se principalmente no aumento da produtividade do trabalho e na redução correspondente do valor da força de trabalho - a mais valia relativa em sua forma clássica -, se baseia largamente em modalidades historicamente regressivas de exploração, tais como as discutidas no presente trabalho.

\section{REFERÊNCIAS}

LUCE, M. S. A superexploração da força de trabalho no Brasil. Revista da Sociedade Brasileira de Economia Política, São Paulo, n. 32, p. 119-141, jun. 2012. Disponível em: <http://www.sep.org. $\mathrm{br} / \mathrm{revista} /$ download?id=230 $>$. Acesso em: 6 out. 2013.

MANDEL, E. O capitalismo tardio. São Paulo: Abril Cultural, 1982.

MARINI, R. M. Dialéctica de la dependencia. México: Era, 1973.

El ciclo del capital en la economía dependiente. In: OSWALD, U. (Coord.). Mercado y dependencia. México: Nueva Imagen, 1979a.

. Las razones del neodesarrollismo (respuesta a F. H. Cardoso y J. Serra). Revista mexicana de sociología, México, n. esp., p. 57-106, 1978.

Plusvalía extraordinaria y acumulación de capital. Cuadernos políticos, México, n. 20, p. 1839, abr./jun. 1979b.

MARX, K. O capital: crítica da economia política. São Paulo: Abril Cultural, 1983a. Livro I, tomo 1.

O capital: crítica da economia política. São Paulo: Abril Cultural, 1984a. Livro I, tomo 2.

O capital: crítica da economia política. São Paulo: Abril Cultural, 1984b. Livro III, tomo 1.

Teorias da mais-valia: história crítica do pensamento econômico - Livro IV de O capital. São Paulo: DIFEL, 1983b. Volume II.

Teorias da mais-valia: história crítica do pensamento econômico - Livro IV de O capital. São Paulo: DIFEL, 1985. Volume III.

OSORIO, J. Crítica de la economía vulgar: reproducción del capital y dependencia. México: Miguel Ángel Porrúa, Universidad Autónoma de Zacatecas, 2004. Disponível em:<http://www. estudiosdeldesarrollo.net/pagina_tipo_cuatro. php?libro=critica_de_la_economia>. Acesso em: 18 mar. 2010.
ROSDOLSKY, R. La sección sobre el proceso de producción. In: . Génesis y estructura de EI capital de Marx: estudios sobre los Grundrisse. 4. ed. México: Siglo XXI. 1985. p. 201-348.

SERRA, J.; CARDOSO, F. H. As desventuras da dialética da dependência. Estudos CEBRAP, São Paulo, n. 23, 1980. (Publicado originalmente na Revista mexicana de sociología, México, número especial, 1978.)

\section{NOTAS}

1 Veja-se, por exemplo, Serra e Cardoso (1980). O artigo foi publicado originalmente em 1978 na Revista mexicana de sociología. No mesmo número foi publicada a resposta de Marini (1978).

2 Luce (2012) chama a atenção para a inclusão, em Marini (1978), de um quarto mecanismo, a saber, o aumento do componente histórico-moral do valor da força de trabalho. Embora a exposição que se segue não trate dele especificamente, as indicações feitas a propósito dos demais mecanismos certamente permitirão compreendê-lo sem maior dificuldade.

3 A análise aqui empreendida se restringe à manifestação do fenômeno da superexploração no âmbito das economias dependentes. Escapa, portanto, aos objetivos do presente trabalho um exame da possibilidade de outras manifestações do fenômeno (especificamente, sua identificação nas economias capitalistas avançadas).

4 Ver Marini (1973), especialmente a seção 2 - O segredo da troca desigual. Conquanto as transferências de valor aí consideradas sejam aquelas que se dão no âmbito do comércio internacional, o argumento pode ser estendido às transferências associadas ao investimento estrangeiro nas economias dependentes.

5 O trecho entre aspas citado por Marini é extraído do capítulo XXII do livro I de O capital (MARX, 1984a, p. 178).

6 Do mesmo modo, em Plusvalía extraordinaria y acumulación de capital, lemos: "[...] dada a superexploração do trabalho, isto é, o fato de que a força de trabalho se remunere abaixo de seu valor [...]" (MARINI, 1979b, p. 33).

7 Não nos deteremos no exame dessa questão, particularmente relevante no que diz respeito às diferenças de taxas de mais-valia entre economias avançadas e dependentes.

8 Esse ponto é bastante destacado por Osorio (2004). Explica o autor: "[...] o fato de que pelo nível de abstração em que se move a análise em O capital não se aborde o tema da violação do valor da força de trabalho não significa que o fenômeno fosse desconhecido por Marx ou que o considerasse um assunto irrelevante. Muito ao contrário, os limites que se autoimpõe por razões de método, a fim de desentranhar a lógica que 
organiza, articula e reproduz a economia burguesa, o levam a não analisar o problema." (OSORIO, 2004, p. 92).

9 Osorio (2004, p. 94, grifo do autor) defende uma posição semelhante com respeito ao papel da luta de classes: "Em definitivo, não é a luta de classes que determina o valor [da força de trabalho], mas é este que define o eixo em torno do qual se desenvolverá a luta de classes." Para um ponto de vista distinto, isto é, de que a luta de classes incide sobre o próprio valor da força de trabalho, ver Mandel (1982, p. 110-111).

10 Por simplicidade da exposição, o salário é aqui considerado como equivalente ao preço da força de trabalho.

11 Marini (1979a, p. 50) aponta um dos fatores dessa expansão: "Na economia dependente, esse exército industrial de reserva tende a crescer a partir do momento em que se introduzem (principalmente através do capital estrangeiro) novas técnicas de produção, desenhadas para economias onde a mão de obra é relativamente escassa [...]. Reduz-se em consequência a capacidade do capital para empregar mais mão de obra, fazendo com que o exército operário ativo cresça a um ritmo lento, o que resulta como contrapartida em expansão rápida do exército de reserva."

12 O problema já havia sido identificado por Marx (1984a, p. 22) com referência aos países em que o modo de produção capitalista está mais desenvolvido: "A própria máquina, em países há mais tempo desenvolvidos, produz, por sua aplicação em alguns ramos de atividade, tal excesso de trabalho (redundancy of labour, diz Ricardo) em outros ramos, que aí a queda do salário abaixo do valor da força de trabalho impede o uso da maquinaria e torna-o supérfluo, frequentemente impossível, do ponto de vista do capital, cujo lucro surge de qualquer modo da diminuição não do trabalho aplicado, mas do trabalho pago." Ao citar essa passagem, Marini (1978, p. 87, grifo do autor) faz o seguinte comentário: "Em países de desenvolvimento recente, poderíamos dizer, isso se dá ainda com mais força, uma vez que o emprego de maquinaria incide sobre uma força de trabalho que se remunera já abaixo de seu valor." No mesmo sentido, argumenta Mandel (1982, p. 39), ao tratar da produção de matérias-primas nos países dependentes na etapa do imperialismo clássico: "O enorme volume de força de trabalho a baixo preço, em disponibilidade nessas regiões, tornou não lucrativo o emprego de capital fixo em grande escala: a máquina moderna não podia competir com esse trabalho barato."

13 "A força de trabalho só se realiza, no entanto, mediante sua exteriorização, ela só se aciona no trabalho. Por meio de sua ativação, o trabalho, é gasto, porém, determinado quantum de músculo, nervo, cérebro etc. humanos que precisa ser reposto. Esse gasto acrescido condiciona uma receita acrescida. Se o proprietário da força de trabalho trabalhou hoje, ele deve poder repetir o mesmo processo amanhã, sob as mesmas condições de força e saúde. A soma dos meios de subsistência deve, pois, ser suficiente para manter o indivíduo trabalhador como indivíduo trabalhador em seu estado de vida normal." (MARX, 1983a, p. 141). Na edição do livro I de O capital da Boitempo, em vez de "condiciona", temos "implica", o que parece expressar melhor o pensamento de Marx sobre esse ponto.

14 Na edição da Abril Cultural, aqui utilizada, em vez de "remuneração", aparece "restauração". Corrigido de acordo com a edição Siglo XXI (tomo I, vol. 2, p. 639, 13. ed., 1987).

15 A interpretação segundo a qual o pagamento de um salário diferente do valor da força de trabalho implica a fixação de um tempo de trabalho necessário diferente do necessário para reproduzir o valor da força de trabalho, com repercussão sobre o tempo de maistrabalho e a mais-valia, não é aceita consensualmente entre os intérpretes. Voltaremos a esse ponto.

16 Ou, como lemos em Teorias da mais-valia: "Todavia, essa intensificação, se ocorrer apenas em determinados ramos, corresponderá a trabalho composto, trabalho simples potenciado. Nesse caso, menos de uma hora intensiva monta a tanto quanto uma hora extensiva e outorga o mesmo valor." (MARX, 1985, p. 1354).

17 Em outro lugar, Marx (1984a, p. 107, grifo nosso) esclarece: "Assim que o modo de produção capitalista esteja estabelecido e se tenha tornado o modo geral de produção, a diferença entre mais-valia absoluta e relativa torna-se sensível tão logo se trate de aumentar a taxa de mais-valia em geral. Pressupondose que a força de trabalho seja paga por seu valor, encontramo-nos frente a estas alternativas: dada a força produtiva do trabalho e seu grau normal de intensidade, só é possível aumentar a taxa de maisvalia mediante prolongamento absoluto da jornada de trabalho; por outro lado, dada a limitação da jornada de trabalho, só é possível aumentar a taxa de maisvalia mediante mudança da grandeza de suas partes integrantes, trabalho necessário e mais-trabalho, o que, por sua vez, se o salário não deve cair abaixo do valor da força de trabalho, pressupõe mudança na produtividade ou na intensidade do trabalho". Essa semelhança entre aumento da intensidade e da produtividade do trabalho no tocante à redução do trabalho necessário é também apontada por Mandel (1982, p. 103) e Rosdolsky (1985, p. 260).

18 Justamente devido ao seu efeito de redução do tempo de trabalho necessário é que consideramos a intensificação do trabalho como um método de produção de mais-valia relativa. Marini tem o mesmo ponto de vista, pelo que chama a atenção para a necessidade de não se identificar superexploração com mais-valia absoluta. Ver Marini (1973, p. 92).

19 Em outro trabalho, Marini (1978, p. 98, grifo do autor) observa: "Sabemos, com Marx, que qualquer variação na magnitude extensiva ou intensiva do trabalho faz variar no mesmo sentido o valor da força de trabalho. O prolongamento da jornada e o aumento da intensidade do trabalho acarretam um maior gasto de força física e, portanto, um desgaste maior que, dentro de certos limites, incrementa a massa de meios de vida necessários à sua reposição. Os métodos de 
superexploração acima mencionados [...] implicam, pois, uma elevação do valor da força de trabalho [...]".

20 Note-se que, na situação retratada, a fixação de um preço inferior ao novo valor da força de trabalho constitui uma condição para o incremento da taxa de mais-valia. É esse o sentido da seguinte afirmação de Marini (1979b, p. 25) a propósito do aumento da intensidade do trabalho: "Assim, para que se eleve a taxa de mais-valia, ou pelo menos para que se eleve em grau mais que proporcional ao aumento da intensidade do trabalho, será necessário que - independentemente de que aumente o preço e o salário da força de trabalho - esta seja remunerada abaixo de seu valor, isto é, seja objeto de uma superexploração."

21 Marini (1973) considera que esse caso não deve ser interpretado como uma forma de produção de maisvalia absoluta, argumentando que as duas partes da jornada de trabalho são afetadas, e não apenas o tempo de mais-trabalho, no que parece ter razão. Com efeito, embora o tempo de trabalho necessário para reproduzir o valor normal da força de trabalho não se altere, o pagamento de um salário abaixo desse nível implica um tempo de trabalho necessário efetivamente menor.

22 Mandel (1982, p. 103) também admite esse efeito da redução do salário sobre o tempo de trabalho necessário e sobre a taxa de mais-valia: "Se a duração da jornada de trabalho permanecer a mesma [...], a taxa de mais-valia deverá elevar-se de acordo com as condições apresentadas a seguir: [...] se, inalterada a produtividade ou intensidade do trabalho (e, a fortiori, com um crescimento na produtividade e intensidade do trabalho), houver uma queda no salário real, isto é, se o equivalente em valor do salário puder ser produzido numa fração menor da jornada de trabalho."

23 Ver Marx (1984b, p. 179).

\section{Elizeu Serra de Araujo}

Economista

Doutor em Políticas Públicas pelo Programa de PósGraduação em Políticas Públicas da Universidade Federal do Maranhão (UFMA)

Professor Adjunto do Departamento de Economia e Professor do quadro permanente do Programa de PósGraduação em Desenvolvimento Socioeconômico da UFMA

E-mail: elizeuserra@yahoo.com

\section{Universidade Federal do Maranhão - UFMA}

Av. dos Portugueses, 1966 - Bacanga, São Luís/MA CEP: $65080-805$ 